\title{
Review
}

\section{The Art of the Possible in the}

\section{Arab-Israeli Crisis}

\author{
Michael C. Hudson†
}

The Art of The Possible: Diplomatic Allernatives in the Middle East. By Michael Reisman. Princeton: Princelon University Press, 1970. Pp. 161. $\$ 6.00$ (hardbound), $\$ 1.95$ (paperback).

The Arab-Israeli conflict is one of the most studied and talked about problems in modern international affairs. From the earliest days of the Mandate, a succession of voluminous official reports, white papers, and serious partisan studies have emerged purporting to point the way toward a solution. Since the 1967 war there has been no dearth of governmental, congressional, and academic brainpower expended toward the same end. Yet despite the impressive aggregation of analytic talent, the problem still eludes solution, making it one of the oldest permanent crises still with us. The problem itself is all too familiar-competing nationalisms, holocaust, war, displacement of the Palestinians, incursions, reprisals, belligerency, blockades, threats, more war, apparently ad infinitum. No less familiar are all the options that have been proposed over the years-binationalism, partition, internationalization, compensation, repatriation, open waterways, arms control, truce supervision, refugee relief, and peacekeeping. The familiarity of these options has come to be matched only by their apparent sterility.

Thus when proposals come along that attempt to break new ground and show some degree of creativity and imagination, they deserve serious scrutiny. Michael Reisman's eighty-eight page essay falls in this category. His approach exemplifies what one may call a liberal perspective on the problem, as distinguished from the radical positions found among many of the partisans, who call for a drastic altering of the pre-1967 status quo in favor of one side or the other. Reisman's is a breathtakingly sweeping approach. At a single stroke he cuts away 


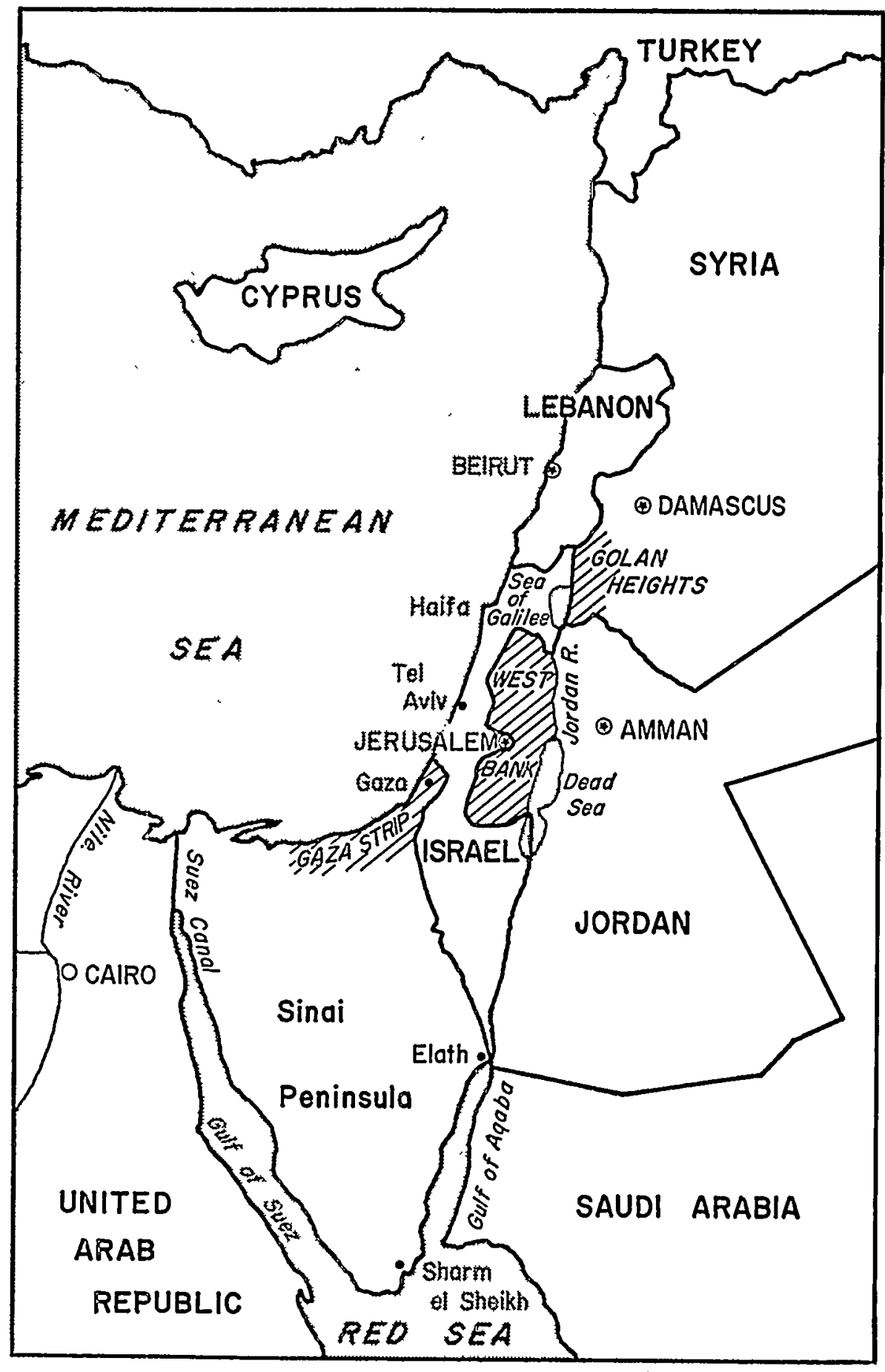

Map reprinted from M. Riessis,

The ARt of the possinle: DHLlomatic Alternatives in the Midde Last 2 , (C) 1970 , by permission of the Princeton University l'ress 
all the past claims and counterclaims of the various parties. ${ }^{1} \mathrm{He}$ is sensitive to the moral ambiguities of the situation and critical of the interferences of the outside powers. He sympathizes with the people, Jewish and Arab, who have suffered injustices; and he has generally harsh words for the leadership, particularly Arab, whose pettiness, parochialism, stupidity, and destructive fantasies have exacerbated the crisis.

He predicates his discussion on an image of the Middle East as "a regional multipolar arena, which will continue to be unstable because of fragmentary development and the ambitious and conflicting goals of various national elites there."- As the Middle East is a particularly volatile part of the "global village" that we all inhabit, according to Mr. Reisman, it is appropriate for the Great Powers to "help create the conditions for minimum order in the region, to lower the level of overt violence, to isolate or neutralize the initiators of unrest, and to resolve the major moral and human problem-the plight of the Palestine refugees-in the most equitable manner possible." 3 Active participation by the big powers is important because they are already inextricably involved in the conflict and because the local actors seem to be unwilling or unable to make peace themselves. His solution is forthright: a Sinai development trust, a Druze trust territory in the Golan Heights, a Palestinian state on the West Bank, and an "international" statute for an Israeli-controlled Jerusalem. Having conceived the ArabIsraeli problem in its larger dimensions-both international and socialReisman proceeds rationally to break it down into "manageable" separate problems and then to apply his considerable ingenuity in international law toward a set of smaller solutions.

\section{A General Critique}

Despite its grandiose rhetoric, the essay is a serious effort to apply novelty and ingenuity to the Arab-Israeli problem. It is not a propaganda brief for the Israelis-although sometimes it reads like one; nor is it just a safe rehash of old positions. Inventive as it is, however, I think it fails as a viable solution to the crisis. The underpinning of the Reisman proposals is a set of questionable assumptions about the area and the situation. In some cases the assumptions themselves are unfounded; in others the inferences drawn from them are incorrect. The

1. See M. Reisman, The ARt of the Possible: Diplomatic alternatives in tie MiddeE EAST 4 (1970) [hereinafter cited to page number only].

2. P. 88 .

3. $I d$. 
overall result is a set of "alternatives" that is not consistent with the realities of the Arab-Israeli conflict.

A. Reisman is right in acknowledging that the region is in flux but he discounts one of the primary reasons for it-Arab nationalism. To. day the Arab world is incoherent and divided, and its political leaders are seemingly irrational. But there is logic to Arab behavior that any analyst of the Arab-Israeli conflict must consider, which derives from the persistent and powerful appeal to Arab nationalism. The aims of pan-Arabism have been the return of Palestine to the Arab nation and the destruction of deviationist regional state nationalism. Egypt under Nasser from around 1955 to 1961 was considered by most Arabs to be the vanguard of Arab unity, and Nasserite interference in other regimes was widely approved. It may be easy to ridicule the movement for its failures and chauvinism, but it is a mistake to derogate its hold on elites and masses alike. The mistake is all the more serious because political institutions are exceedingly fragile in the Arab world: elites are constantly subject to the threat of sporadic, unstructured outbursts of popular "participation" which can undermine local regimes of low legitimacy. To underestimate Arab nationalism leads to the erroneous conclusion that the locus of instability is in the political lendership, and is the result of personal ambition or irrationality.

B. The harsh blame Reisman places on established elites in the Arab world indicates an assumption that they function in a political vacuum, and ignores the significance of radical counter-elites and mass public opinion as the primary "destabilizing" and militant forces in the Arab states.

He suggests that the deficiencies of Arab leaders as individuals account for much of the problem: Nasser's pan-Arabism was a vision of "personal imperialism";" and "[i]t is neither Israel nor the United States that hardens or softens the heart of Pharaoh; it is Mr. Arafat and, increasingly, his own extremist fleas." 5 In this characterization, Reisman reflects the regrettable tendency of Washington policymakers to personalize the Middle East problem: "if only we could replace Nasser our troubles would be over." Such statements are not altogether wrong, but they are highly misleading. For Reisman, therefore, the problem of keeping minimum order in the Middle East is to a large extent one of "skirting the shortsighted obstinance of a number of elite

4. P. 28.

5. P. 13. 


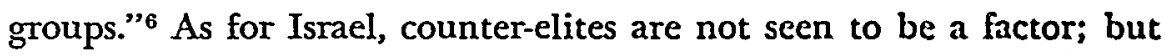
public opinion is more potent than in the Arab world, and it is deeply skeptical of the compromises which a United Nations or United Statessponsored diplomatic settlement would require.

C. By starting with the precept that the Great Powers have a responsibility to create minimum order and neutralize unrest, Reisman endorses a policeman function which the United States especially should abjure. Furthermore, the conditions of instability in the Middle East are so pervasive-as the author himself rightly notes-that such a role is as difficult and costly as it is morally questionable.

Reisman is not alone in using "instability" in a pejorative sense: diplomats and international lawyers are professionally committed to maintain and search for order. But Israel is willing and able to sacrifice an agreed settlement providing minimum order for its own vision of national security; Egypt and the other Arab states directly involved want their territorial integrity and security from future invasion first; the Soviet Union may prefer minimum disorder to the extent that it needs to solidify its impressive gains in the Arab world; and the Palestinian resistance movement is the most categorical of all in rejecting the idea of minimum order. The United States may be the only principal party for which a solution involving agreed minimum order and eventual peace is the highest priority; yet even Washington seems to feel it may benefit from backing Israel's position. Instability in the Middle East may be anathema to Mr. Reisman, but to important elements inside and outside the area, instability, if not a good in itself, is a hopeful indicator of innovation and progress. These elements see the Great Powers" "responsibility" for minimum order as neo-imperialism.

D. Reisman commits the fallacy of "separate packagism" in assuming that the Middle East crisis is really a set of relatively distinct and independent problems. To be sure, there are some reasons for supporting such an idea. The interests of the Palestinian refugees would seem to be quite separable from those of states, and the political context of Sinai is clearly different from Jerusalem. Egypt has indicated that it might be interested in a separate accommodation with Israel over the Suez Canal and Sinai even though it has also maintained that not one inch of Arab territory will be sacrificed. Yet the feasibility of separate packagism depends on the extent to which the various Arab actors are

6. $\quad$ P. 88 . 
actually autonomous from one another. Reisman's defective vision of the Arab world leads to a defective analytic strategy. To a far greater extent than he suggests, the Arabs are aware of the indivisibility of the Israeli challenge. On a tactical level, Arab diplomats perceive that piecemeal solutions only weaken them further. Arab politicians and the rising counter-elites exemplified by students and professionals tend to feel the same way. Looking farther ahead, it is hard to imagine that a set of separate solutions as proposed by Reisman, even if they all were formally concluded, would bring minimum order: Arab claims to full sovereignty in Sinai, Jerusalem, and Golan would hardly disappear, regardless of what particular regimes decided; nor would the struggle of the Palestinian resistance and their supporters be stilled. Conversely, a powerful Israel would tolerate nothing less than effective control, direct or indirect, in the conquered territories. The more likely result -a "solution" on one or tro issues only-would be even less satisfactory. A separate deal between Egypt and Israel over Suez or even Sinai might buy time, but in the long run it would prove untenable if the questions of refugees, Jerusalem, the West Bank, and Golan remained unresolved or ignored.

E. Finally, Reisman places considerable store in what one might call the ethnic ploy. In emphasizing the local, fragmentary, and primordial nature of political culture in the Arab East, he is in good company, for scholars are now beginning to appreciate more fully these characteristics. This is one sociological issue with high political salience because it challenges the myth of a dominant Arab political identity. Thus Mr. Reisman finds it possible to suppose that if Egyptians, Palestinians, ${ }^{7}$ and Druze ${ }^{8}$ can be given specific concessions to their particularistic communities, then the generalized Arab hostility to Israel will prove to have been a paper tiger. Whether or not Reisman's proposals to strengthen parochial identities would indeed result in harmony is presumably not relevant to the strategic issue: for even if conflict persisted it would be deflected away from Israel, toward inter-Axab quarrels-Druze against Sunni, Palestinian against Jordanian, Egyptian against all other Arabs. The ethnic ploy is of course a logical derivation

7. On the plight of the Palestinians, still without a national-statc a quarter-century after the initial resolution of the United Nations General Asscmbly, see pp. 44.49, and the text of that resolution at 102-29.

8. There are about a quarter-million Druze living in Syria, Lebanon and Isracl. They have existed as a distinct religious sect for almost a thousand years, but have never developed a national or ethnic political movement. On Reisman's proposal for a Druzc Trust Territory see pp. $1252-53$ infra. 
of the image of a highly-fragmented Arab political culture. But if, as I have suggested, the factor of common Arab identity and nationalism has been incorrectly minimized, then the utility of the ethnic ploy is correspondingly reduced.

\section{Reisman's New Perspective and Current Realities}

To tell whether Mr. Reisman's proposals are good examples of the "art of the possible," we should examine them in the context of post1967 diplomacy and politics in the Middle East. U.N. Resolution 242 of November 22, $1967^{\circ}$ has served as the touchstone of all serious efforts to settle the Arab-Israeli crisis since the June war. It calls for "[w]ithdrawal of Israel armed forces from territories occupied in the recent conflict" in return for guarantees of freedom of navigation through international waterways, a just settlement of the refugee problem, and the territorial inviolability and political independence of every state in the area through measures including establishment of demilitarized zones. Although both the United States and the Sovict Union were signatories of the resolution, their subsequent disagreements over its interpretation paralyzed its effective implementation, continually frustrating the efforts of Ambassador Jarring.

In late 1969, Secretary of State William Rogers elaborated the American understanding of a comprehensive settlement within the terms of the Resolution: territorial adjustments were to be "insubstantial," unilateral action by any party on Jerusalem was unacceptable, and a permanent peace was to be sought that would take into account the aspirations of the refugees and the legitimate concerns of the governments involved. As if to underline its commitment to the "evenhandedness" first declared by Governor William Scranton in 1968, the United States delayed action on Israel's request for more Phantom fighter-bombers. Then in June $1970 \mathrm{Mr}$. Rogers initiated the successful United States proposal for a cease-fire along the Suez Canal, and in October 1971 raised the possibilities of an interim, partial settlement over Suez between Egypt and Israel. These American efforts were well-conceived and the Suez cease-fire was a notable success. But the United States failed to use its influence to begin to implement the substance of the U.N. Resolution and Rogers' proposals. Despite compelling strategic reasons to reach a settlement, American policymakers made haste very slowly. Why they allowed their promising initiatives to stagnate is a

9. Reprinted at pp. 157-58. 
complex question: doubtless domestic Jewish influence was a serious impediment. But possibly more important was a distorted strategic vision of the Middle East-carefully nurtured by the Israelis-that a stronger "Greater Israel" was the only possible bulwark against the Soviet threat. One suspects that this unrealistic realpolitik was concentrated in the White House and the CIA, while some officials in the State Department and the Defense Department saw correctly that the crucial problem of United States policy vis-à-vis the Russians was to regain the confidence, if not the friendship, of Arab elites and public opinion.

The Soviet Union, meanwhile, was consolidating its expensively-purchased gains in the Arab world by pledging complete solidarity in the diplomatic struggle and supplying carefully-limited amounts of essentially defensive military aid. Moscow's interpretation of the U.N. Resolution was explicitly pro-Arab, and varied from the American interpretation: it insisted on complete Israeli withdrawal from all the Arab territories occupied in 1967. Israel's deep penetration raids over Egypt beginning in January 1970 led to a new commitment of Soviet assistance in the form of SAM antiaircraft missiles and a further enlargement of the Soviet contingent of military advisors. With Americanmade aircraft killing Egyptian civilians, the situation was ideal for the expansion of Soviet air and naval facilities. Finally, in May 1971 the Soviets concluded a fifteen-year friendship treaty with Egypt. The Soviet government remained committed to a peaceful settlement, but it seemed clear after four years that it was not in as much hurry as the United States to reach a settlement. The Soviets seemed willing to risk new explosions in order to continue to make marginal gains at American expense.

I have already suggested that the Reisman proposals rest on certain faulty assumptions about Middle Eastern political culture and processes. How appropriate are they in light of the complex and ambiguous maneuvers of the Great Powers toward a settlement? Reisman's indictment of the diplomats is blunt: "Unknowingly, our present peacemakers are programming the next war. The challenge of creative diplomacy is how to avoid it." 10 We are told that the perspectives of the Great Powers are "childlike in their egocentricity"; that they are "muscle-bound" and incapable of exerting significant influence over their clients. Nevertheless, he writes, the superpowers are deeply involved and share important common interests in opening the Suez

10. P. 9. 
Canal and controlling a local arms race that could all too easily lead to nuclear conflict and a confrontation between the United States and the Soviet Union.

A new perspective is needed, and Reisman proposes one with four points: (1) the goal of peace should give way to minimum order; (2) the integrated nature of Middle East problems should be questioned; (3) the rhetoric of imposed versus indigenous solutions must be scrapped; and (4) the need for political and social invention must be recognized. ${ }^{11}$

The fourth point is hortatory: nobody will object to creative thinking on the Middle East. Nor is there any quarrel with the third point; Reisman is correct in noting that the Powers are engaged to the hilt on all sides. But that is quite obvious. Only the militants-Israclis and Palestinians-have articulated this false dichotomy and opted for an "indigenous" solution. Reisman's second point is fair enough: the integrated nature of the crisis is worthy of reexamination, but as I have tried to suggest above his interpretation is seriously misleading. Thus the "separate packages" approach he advocates is probably inadequate.

The first point, however, reveals the essence of the "new perspective," and behind its appealing modesty lies a mischievous conception. How sensible to argue the futility of comprehensive solutions, permanent settlement, and regional peace that Mr. Rogers has tried so valiantly to promote! None will gainsay Reisman's comment that the area is likely to experience chronic instability with or without Israel, no matter what the Great Powers do. But Reisman underplays the enormous turmoil that the Arab-Israeli conflict has generated in the area and its repercussions for Great Power confrontation. It would be better to grasp the nettle of this difficult but clearly defined source of tension than to pursue the chimera of minimum order by constructing machinery for shoring up the present unstable status quo. Behind the rhetoric of a new perspective lurks a rather pedestrian diplomatic vision: the legitimation of the Arabs' territorial and political defeat. Ironically, a minimum-order perspective would, if put into effect, undoubtedly perpetuate the very condition it designed to alleviate-maximum disorder. In the post-1967 situation, Reisman's perspective is in effect a set of technical measures-trusteeships, development schemes and the like-for solidifying the position of Greater Israel. "Greater" not through continued direct rule in the conquered territory, but through the neutralization there of Arab nationalism. In all fairness,

11. Pp. 19-20. 
the Reisman perspective is rather moderate compared to the demands of many Israelis and their American supporters, and many Israelis would find them unacceptable. Thus it would seem to represent a useful step toward "evenhandedness." But I fear that it is a sidestep rather than a step forward, and that it would not achieve either minimum order or peace.

\section{Feasibility of the Specific Proposals}

The history of liberal thinking on war and peace abounds with assumed conclusions. If only rational leadership prevailed, the common advantages of cooperation over conflict would be perceived. To many publicists the key to peace lies in devising specific plans through which the vision of liberal harmony would prevail. In the Middle East, economic development and refugee resettlement programs have been frequently advanced as routes to peace, but they have failed because their implementation depended upon a prior realization of the goal they were designed to achieve. The central issue in the Arab-Israeli conflict is the conflicting claims to Palestine of Israelis and world Jewry, on the one hand, and Palestinian Arabs and the Arab "nation," on the other. Although the Arabs have been beaten three times, each time more decisively than the last, their claim not only persists but has gained intensity. Do the Reisman proposals manage to avoid assuming conclusions and address the main issue? No overall answer is possible. Each component of his proposal must be examined separately.

\section{A. The Sinai Development Trust (SDT)}

The most important of Reisman's separate problems is the conflict between Egypt and Israel, the two main local powers involved in the Middle East crisis. His proposal envisages neutralizing Sinai for perhaps fifty years and establishing an internationally-operated development corporation. Enormous amounts of international, Israeli and Egyptian capital would be poured into this mammoth project to make the desert bloom; nuclear technology would help make it possible. When completed, it would revert to Egyptian control, and because of its location between the two nations, it would serve as a hostage to the aggressive ambitions of both parties. ${ }^{12}$

Even if such a program were economically feasible-which is highly doubtful-it suffers from equally serious political defects. It would re-

12. Chapter II, pp. $23-43$. 
quire the most saintly attitudes on both sides to engender the cooperation necessary for such a grandiose scheme. But none is more scathing than Mr. Reisman himself in depicting the irrationality and avarice of the Egyptian elite and the unlikelihood that these qualities will disappear. The officers are arms-hungry, Egypt itself is one of the "warprone" states, and its ambitions to dominate the area are well-known.13 If these one-sided characterizations were true, Reisman's assertions that "Israel's public stance in the Middle East has, since 1948, been nonexpansionist," 14 would not seem enough to persuade the parties to take the risks entailed by the plan. But it is not necessary to resort to caricature to reveal the flaws in the SDT. The comparatively moderate Egyptian leadership has made major advance concessions to facilitate a diplomatic settlement, but it does seem to have drawn the line at sacrificing Egyptian sovereignty in Sinai. Perhaps to Mr. Reisman "returning the Sinai Peninsula is not the pressing matter," 15 but it is very much on the minds of the Egyptians, and a fifty year freeze on that issue would seem to be asking a great deal. The toughminded Israeli leadership would be similarly ill-disposed to abandon Israel's de facto sovereignty and security in Sinai merely in the hope that shared material advantages in the future would destroy the seeds of conflict. As for the Russians, one would have to push to grotesque extremes the unfashionable argument that they want to reduce their presence to envisage them acquiescing in the SDT.

\section{B. A Druze Trust Territory}

The ethnic ploy is not new in Middle East diplomacy. The French were among its more notable practitioners during their mandate over Syria and Lebanon, and they experimented for a time with dividing Syria into separate autonomous districts in order to repress rising nationalist hostility. ${ }^{16}$ Now that Israel is an occupying power it is not surprising that the doctrine of divide and rule should have some appeal. Furthermore, the complex political culture of the Arab East supports such thinking, but not as completely as Mr. Reisman would have us believe. Anyone who has carefully observed Arab politics since World War II, if not before it, would be unable to accept Mr. Reisman's characterization of Arab nationalism as "often ... nothing more than

13. Pp. 24-25.

14. P. 38.

15. P. 28.

16. See, e.g., S. LoNgrigg, Syria ANd Lebanon UNder Frencit MIANdate ch. 4 (19j3). 
the ambitions of particular political elites."17 By the same token, his conception of Middle Eastern culture as an aggregation of mutuallyhostile, parochial ethnic groups, each with its own subliminal urge for national sovereignty, distorts and over-simplifies. The actual situation is more accurately portrayed by Carleton Coon's metaphor of the cultural mosaic: an integrated network of distinct subcommunities living together by living apart. Although the Druze certainly have a very strong sense of their special identity, they are hardly as hostile to or culturally distant from their Arab neighbors as Reisman suggests. There is no Druze national movement. Druze are not exclusively found in Golan but also in Syria's Jebel Druze and Lebanon. That the Druze in Israel have been given special status is not very persuasive evidence that they will accept a role in legitimizing the dismemberment of Syria. Many Druze outside Israel have been active in the cause of Arab nationalism in its various forms. The Druze speak Arabic and their religion, though heterodox, is rooted in Islam. ${ }^{18}$ The Druze-inspired up. rising against the French mandate in 1925.27 was supported by many non-Druze elements and has become part of the myth of Arab nationalist resistance to imperialism..$^{19}$

But apart from this serious misperception of Arab political culture, one must ask whether the application of League of Nations formulas to the Arab world of the 1970s is feasible. Decades of bitter experience with western avarice cloaked in the rhetoric of "self-determination" and "preparation for self-government" have made the Arabs a good deal less credulous than they were in 1920. More important, the Arabs -even in defeat by Israel-are not as powerless and structurally under. developed as they were when the World War I mandates were put into force. It would be difficult indeed for Arab elites and public opinion to accept further balkanization of the Arab world.

\section{A Jerusalem Statute}

Mr. Reisman lays the groundwork for his proposal on Jerusalem by asserting that the city has far greater religious significance for Jews than for Muslims or Christians..$^{20}$ Such an assertion (particularly with respect to Christianity) is debatable, but even if it should be supported by an ecumenical panel of theologians it would hardly lessen the in-

17. P. 63. See, e.g., M. Berger, The Arab World Today 322-81 (1962) and H. Sinarau, NATIONALISM AND REVOLUTION IN THE ARAB WORLD 67-105 (1966).

18. See generally P. Hitri, The Origins of the Druze Peolle and Religion (1928).

19. See E. Maccallum, The Nationalist Crusade in Srria chs. 6 \& 11 (1928).

20. P. 73 . 
tense, deeply-rooted attachment which Muslim and Christian Arabs hold for the city. Westerners have not paid as much attention as they should have to the absolutely central importance of the Jerusalem issue to the Arabs. More than any other aspect of the crisis, it unites Arabs of all classes, traditions, and ideological persuasion. Whether or not this passion is commendable or legally or theologically sound, it is a political fact, and one does not advance the search for a solution by minimizing it. Jordan's juridical title is as contestable as Isracl's, but the fact that there now may be other Arab (c.g., Palestinian) claimants to Jerusalem hardly reduces the force of the Arab claim in general-it is instead evidence that the Arab nation as a whole has a stake in the city.

Under Reisman's plan, a committee of four-representing Isnel, Jordan, the Palestinians, and Jerusalem's religious groups-would formulate an international statute, with guarantees of religious freedom, that would place the entire city under a joint mayoral and bicameral council system. An Administrative Tribunal would serve as a constitutional court, with appeal to the International Court of Justice. "Jerusalem would, then, be an Israeli city, operating under a unique statutory system aimed at achieving maximum responsiveness to the needs and desires of an idiosyncratically mixed population."'1

This proposal displays the virtue of simultaneously recognizing Israel's grim determination to retain the Arab city and its inability to serve as sole custodian of its ecumenical character. It also correctly recognizes that the sanctity of Jerusalem to Arab Christians and Muslims, just as to Jews, is not a matter of specific holy places alone-rather, it is a claim to the whole city. Unmentioned but related is the economic importance of the city as a whole to both contending parties.

Once again, however, the proposed solution turns out to be a thinly disguised legitimation of Israeli power and influence-or more precisely, a legitimation of the expulsion of Arab jurisdiction. If the problem of Jerusalem were essentially a problem of municipal home rule there would be much to be said for the Jerusalem Statute. But Jerusa. lem is much more than that, and it is difficult to see how any proposal that concedes juridical or de facto Israeli rule over the Arab city will win Arab acceptance.

\section{A Palestine State}

Reisman's Sinai and Jerusalem proposals are deficient because they presuppose the sort of political settlement that the proposals themselves

21. P. 79. 
would render unlikely. The Golan proposal would require activating a Druze national feeling that does not exist through the mechanism of a trusteeship that is anachronistic in the contemporary Middle East. But Reisman's proposal for the problem of the Palestinians does not appear to suffer from these defects. The Palestinian state would not presuppose a political settlement; it would be a political settlement. And it must be considered an interesting one because it would deliver political benefits to both sides. The Palestinian Arabs, destitute and exploited, would win tangible new benefits and the Israelis would win a pacified eastern border with possible access to the Arab hinterland. Reisman is absolutely right when he declares that "[a]n equitable solution to the problem of the Palestinian Arabs is not only an exigent moral demand but also a crucial requirement for increasing stability in the Middle East.".22 (It is a pity that he shows less sensitivity to the non-Palestinian Arab refugees displaced since 1967-over a half-million Egyptians, according to Egyptian officials, and some 100,000 Syrians, according to United Nations estimates.) The question of equity is central. It is also complex. For one thing, today's young Palestinians are probably more outraged than their fathers at the Zionist takeover of Palestine. Palestine to them is not the West Bank; it is Jaffa and Haifa too. Equity to them is the restoration of a land that was usurped by outsiders with the help of the Great Powers. It has given rise to the doctrine and activity of Al Fatah, which to Mr. Reisman are "strategic fantasies" but nonetheless "a highly effective form of group therapy." If the Palestinians were alone in their irrendentism, such "fantasies" might be scant cause for diplomatic or military worry, but the Palestinians are implanted throughout the Arab world and continue to enjoy a high degree of popular support. This support has not prevented Arab governments from sacrificing Palestinian values to state interests, but it has stiffened the Arab backbone and kept the crisis alive. Palestinian organizations have been able to exert a diplomatic force far beyond their real power because they have been singularly immune to the diplomatic conception of equity.

One of America's most distinguished Middle East ambassadors, Ray. mond A. Hare, has called the Palestinian element the missing piece in the Middle East puzzle. The remaining problem would be to persuade the Palestinians to fit into the space allotted them. By early 1972 the problem had been eased in one sense by the fratricidal strife between the Jordanian army and the Palestinian resistance which so crippled

22. P. 44.

23. Id. 
the latter that it should have been glad to take whatever crumbs the diplomats might throw. Furthermore, as the resistance's presence inside Greater Israel (except for Gaza) remained only sporadic, the process whereby Israel might work out its own separate peace with the Palestinians under its control developed steadily. In another sense, however, the setbacks to the resistance diminished the Palestinian State as the "missing piece" and resuscitated Jordan's claim to speak for Transjordanians and Palestinians alike. Thus by 1972 three elements were contesting for world recognition as legitimate spokesman for the Palestinians: the traditional West Bank leadership acceptable to Israel, the Palestinian notables acceptable to Jordan, and the resistance movement, representing Palestinians elsewhere in the world. Although greatly weakened, the resistance could continue to claim that it represented the free Palestinians. But if it were to win in the long run it would have to reassert its striking power and its ability to galvanize the Arab masses, Palestinian and non-Palestinian. Without such a renewal, it was virtually inconceivable that there would emerge a redefinition of equity at the diplomatic level more favorable than the West Bank entity proposal. Neither Israel nor Jordan would be in any hurry to negotiate the authentic Palestinian goal of a secular, democratic state in all of Palestine unless compelled by circumstances to do so.

Reisman's Palestine state proposal has the virtue of facing the problem, and given the present obstacles facing the Palestinians a development along these lines is not impossible. Were a Palestinian settlement to be worked out, it would clearly reduce the volatility of the crisis as a whole. Large complex puzzles may be hard to solve but if one can discover (or invent) the missing piece then the other parts begin to fall into place. The Palestinians indubitably are at the core of the entire Middle East crisis.

But who speaks for the Palestinians? Unfortunately, Reisman accepts too easily the assessment or the wish of many "sympathetic" diplomats, academicians, and journalists that there is a moderate "silent majority" perhaps best represented by the traditional leadership on both banks of the Jordan. This view, in my opinion, overemphasizes the war-weariness, organizational incompetence, and basic cooperativeness of the Palestinians and it too easily dismisses the resistance movement as a small noisy band of malcontents. If the Palestinians under Isracli and Jordanian control are silent it may be out of prudence rather than preference. An alternative assessment holds that the resistance movement remains the most authentic and legitimate voice of the Palestin- 
ians, and that its revolutionary cadres will not only survive but actually thrive on the present status quo or on any Palestine entity solution now deemed acceptable by the diplomats. If this alternative is valid then it is time to begin developing a Palestine solution that involves the right of return of all Palestinian Arabs to geographic Palestine under a political system of freedom, communal security, and shared authoritya system that guarantees the sanctity of Jewish and Arab political identity symbols and promotes the development of new integrated parties and groupings.

\section{What Is To Be Done?}

The Six-Day War posed two basic diplomatic alternatives; either return to the pre-June 1967 status quo or attempt to fashion a comprehensive solution to the problem. The Soviet Union preferred the former, the United States the latter. What has developed in the post1967 period, however, is neither of these. Rather, we have seen the new status quo of Greater Israel taking root. Certainly this new status quo is far preferable to Israel than either of the others. The Soviet Union also finds that the status quo meets the requirement of perpetuating a condition of controlled tension. For the United States, however, the outcome is less satisfactory, for it has lost both friends and reputation and its interests have fallen in further jeopardy. In response, a new line has been bruited about, which Mr. Reisman's pro. posals typify. The key contention is that real peace was impossible from the start, and that it is naive to seek it. Instead, American policy should attempt to develop Israel-surrogates in Jerusalem, Sinai, the West Bank and Golan, and forget once and for all about Governor Scranton's notion of "evenhandedness." Reisman, to be sure, does not take this as his goal, and he is far less callous toward the Arabs. Yet some of his specific proposals, as I have indicated, would produce the same result. The catch is that the new status quo of a Greater Israel is certain to be even more unstable than the former one. No sugar-coating of trusts, trusteeships, municipality formulae, and Bantustans will hide the reality or neutralize the claims of the Arabs. These devices, however well-intentioned, satisfy the Israeli demand for peace with security without adequately addressing the Arabs' demand for justice. By underestimating Arab grievances against Israel, the author diverts attention from the basic problem, thus making his own relatively apolitical, legalistic propositions seem more plausible. Reisman uses the bitterness and irrationality of the local protagonists as a reason for the Powers 
to avoid facing the question of justice squarely, but if he is right about the intensity of feelings involved, how can we expect success from his proposals, which merely sidestep those feelings?

What then can be done? I think that we should keep in mind the following political factors in trying to formulate an answer: the new status quo is less stable than the old one; the Arabs are not as impotent or divided on the Palestine question as global strategists may suppose; Israel cannot have both territories and peace; the Soviet Union benefits from and wishes to perpetuate a state of controlled tension in which the United States will continue to suffer from its pro-Israel "tilt"; and the United States as long as it interprets "evenhandedness" through distorted lenses, risks its interests in the area, jeopardizes the remaining friendly Arab regimes, and invites the neutralization of its strategic position in the Mediterranean.

Peace is possible if it is accompanied by justice. The main elements have been spelled out and are familiar to all. They were enunciated courageously by Secretary Rogers in December 1969: security, territorial integrity with only insubstantial changes, open waterways, and no unilateral takeovers in Jerusalem. The Administration's allusion to the Palestinian people in February 1970 suggested that it had become officially aware of that crucial missing piece of the puzzle, and thus had established what must be considered a set of fair working principles. These principles are not as pretentious as the Reisman proposals, and are far more just and promising. That American implementation of these principles has faltered since the Suez cease-fire was achieved is primarily due to American, not Middle East politics. The allegedly irrational, small-minded Arab elites were largely won over through patient and astute American maneuvering. But when it came to Israel, the Administration lost the will to apply its massive and unique capabilities for persuasion. Pious apologies to the effect that we lack the power to persuade Israel are ludicrous; they sound strange indeed issuing from the pens of otherwise toughminded policymakers and advisors. After October 1970 it was not Mr. Reisman's Arab world -that "volatile arena" with its "flaring conflicts of ambition"-that was obstructing a just settlement. It was simply the government of Israel. Israel had conducted a masterful policy toward the United States in which cold war reflexes in our foreign policy establishment were harnessed to domestic pro-Israel sentiment.

It may be argued that the Soviet Union would never permit or acquiesce in an evenhanded application of pressure to implement the Rogers principles. Certainly it was placed on the defensive when those 
principles were first announced, and its reaction, exemplified by its inflexible stance in the Four Power talks, was hardly encouraging. As the United States never reached the point of backing its words with actions, however, we cannot really know what the Russian reaction would have been. But if those Soviet specialists who feel that the Rus. sians would like to disengage a bit from their Arab allies are correct, then the possibility of Soviet cooperation surely exists, particularly if they could receive at least half the credit for engineering the settlement. To those who argue that the Soviets would balk for fear that their entire raison d'etre in the Middle East would disappear, it is sufficient to recall that there are several other countries in the Middle East, such as Iraq and Democratic Yemen, where they would remain highly competitive, and that the chronic instability of inter-Arab politics would continue to provide openings-albeit on somewhat less favorable terms.

Failure to implement a just peace immediately after the 1967 war gave an enormous impetus to the forces of radical change in the Arab world, represented mainly by the Palestinian resistance. The guerrilla challenge was temporarily defused after the September 1970 Jordan crisis but only with great bloodshed and American aid to King Hussein. Nasser's death created uncertainties over Egypt's future course, but Anwar Sadat proved, initially at least, an astute successor. Another moment propitious for implementation of the principles had presumably come. But diplomacy got nowhere in 1971, owing largely to the paralysis in the implementation of American policy. American planners allowed themselves to be diverted into working for a Suez Canal interim settlement which could at best buy only a little more time. The broader political aspects of the crisis were at least temporarily ignored -a serious error. The year 1972 began with new promises by Washington to support Israel with Phantoms and military technology. It takes no great prophetic gifts to foresee a continuing growth in Arab militancy, a further weakening of "moderate" Arab leadership in Egypt and the oil-rich Arabian peninsula. To the extent that pessimism over the feasibility of a peaceful settlement has slowed the efforts to achieve one, it has constituted a self-fulfilling hypothesis. Flaccid diplomacy continues to nurture Arab militance and Israeli obstinacy. 